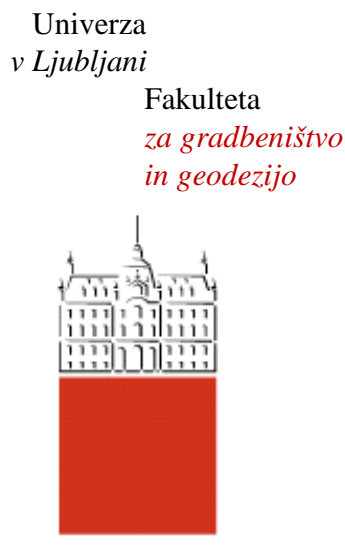

Jamova 2

1000 Ljubljana, Slovenija http://www3.fgg.uni-lj.si/

DRUGG - Digitalni repozitorij UL FGG http://drugg.fgg.uni-lj.si/

Ta članek je avtorjeva zadnja recenzirana različica, kot je bila sprejeta po opravljeni recenziji.

Prosimo, da se pri navajanju sklicujete na bibliografske podatke, kot je navedeno:

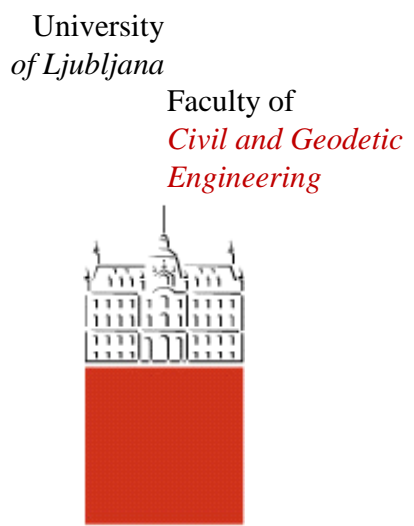

Jamova 2

SI - 1000 Ljubljana, Slovenia http://www3.fgg.uni-lj.si/en/

DRUGG - The Digital Repository http://drugg.fgg.uni-lj.si/

This version of the article is author's manuscript as accepted for publishing after the review process.

When citing, please refer to the publisher's bibliographic information as follows:

Trtnik, G., Kavčič, F. in Turk, G. 2008. The use of artificial neural networks in adiabatic curves modeling. Automation in Construction 18, 1: 10-15.

DOI: 10.1016/j.autcon.2008.04.001. 


\title{
The use of artificial neural networks in adiabatic curves modeling \\ Gregor Trtnik ${ }^{\mathrm{a}, \mathrm{b}}$, Franci Kavčic ${ }^{\mathrm{b}}$, Goran Turk ${ }^{\mathrm{a} 1}$
}

\author{
${ }^{\mathrm{a}}$ University of Ljubljana, Faculty of Civil and Geodetic Engineering \\ Jamova 2, SI-1115 Ljubljana, Slovenia \\ ${ }^{\mathrm{b}}$ IGMAT d.d. Building Materials Institute, Polje 351c, Ljubljana, Slovenia
}

\section{Abstract}

Adiabatic hydration curves are the most suitable data for temperature calculations in concrete hardening structures. However, it is very difficult to predict the adiabatic hydration curve of an arbitrary concrete mixture. The idea of modeling adiabatic temperature rise during concrete hydration with the use of artificial neural networks was introduced in order to describe the adiabatic hydration of an arbitrary concrete mixture, depending on factors which influence the hydration process of cement in concrete. The influence of these factors was determined by our own experiments. A comparison between experimentally determined adiabatic curves and adiabatic curves, evaluated by proposed numerical model shows that artificial neural networks can be used to predict adiabatic hydration curves effectively. This model can be easily incorporated in the computer programs for prediction of the thermal fields in young concrete structures, implemented in the finite element or finite difference codes. New adiabatic hydration curves with some other initial parameters of the concrete mixture can be easily included in this model in order to expand the range of suitability of artificial neural networks to predict the adiabatic hydration curves.

Keywords: Fresh concrete, Adiabatic hydration curves, Experiments, Artificial neural network

\section{Introduction}

Concrete is the most commonly used structural material and is composed of individual base materials. Every base material has some influence on the hydration process of cement in concrete. Of course, cement has the greatest influence being one of the base materials, which is the foundation for hydration process. Hydration is an exotermic reaction during which heat liberates. Increased temperature of mixture caused by heat generation during hydration accelerates the hydration process. Development

\footnotetext{
${ }^{1}$ Corresponding author. Phone: +386 14768 614; fax: +386 14768629.

E-mail address: gturk@fgg.uni-lj.si (G. Turk)
} 
of the hydration heat is one of the most important processes worth observing during setting and hardening of concrete in particular during concreting of large volumes [1]. During hardening of concrete there arise high thermal gradients near the surface of the concrete block as a result of relatively low thermal conductivity. Extensive development of heat of hydration during concreting in summer period may lead to overheating of concrete.

Hydration process of cement in concrete in laboratory conditions is usually the basis for further prediction of behavior of concrete in structures. Development of hydration reactions and processes in qualitative respect may be followed with the aid of monitoring the development of hydration heat by direct and indirect calorimetric methods. Adiabatic heat measurements are the most convenient for producing continuous heat of hydration curves under curing condition close to or almost identical with mass curing [2]. Adiabatic hydration curves would be the most suitable starting point for temperature calculations in hardening structures. Therefore, the adiabatic curves are judged to be of great practical importance.

It is well known $[2,3,4]$, that kinetics and intensity of the hydration process is affected by many factors, such as environmental temperature and moisture content, cement composition, fineness of grinding, water-cement ratio, type of cement, initial temperature of fresh concrete mix, presence of additives and admixtures etc.

There exist numerous empirical equations to predict the adiabatic curves, i.e. the adiabatic temperature rise $T(t)$ of concrete mixture. Morabito [5] for example used the following empirical relationship

$$
T(t)=\frac{t}{n+m t}
$$

where $m$ and $n$ are constants to be determined empirically for each kind of concrete mixture. Kavčič [4] used the equation

$$
T(t)=T_{\infty} \exp \left(-m t^{-n}\right)
$$

where $T_{\infty}\left[{ }^{\circ} \mathrm{C}\right]$ is the temperature at the end of the hydration process. Ammar et al. [6] give the following equation

$$
T(t)=a+b \exp \left(-\left(\frac{c}{t}\right)^{d}\right)
$$

where $a, b, c$ and $d$ are constants to be determined for each kind of concrete mixture. Equations (2) 
and (3) are both mathematical functions that produce a curve having "S" shape with exactly one inflection point.

The main disadvantage of these equations is that the empirical coefficients have to be determined experimentally and specifically for each concrete mix. This is time consuming and hence expensive. Particularly in the design stage of the project, when the designer wants to evaluate the effects of changes in the concrete mix on the temperature and strength development, it would be of great advantage if these input adiabatic curves could be generated with the use of adequate numerical models. Therefore, the successful development of a general formula to predict the adiabatic hydration curve for an arbitrary concrete would be a great advantage. Some numerical programs exist which are able to predict the adiabatic hydration curves for an arbitrary concrete mixture $[2,7]$. In the Van Breugel model [2], the degree of hydration (and corresponding adiabatic hydration curve) is modeled as a function of the particle size distribution and chemical composition of cement, w/c ratio and reaction temperature. The cement particles are modeled as digitized spheres, randomly distributed in a three dimensional body and the hydrating cement grains are simulated as growing spheres. As cement hydrates, the cement grains gradually dissolve and a porous shell of the hydration products is formed around the grains. This result in an outward growth or expansion of the particles. These hydrates first cause the formation of small isolated clusters. Big clusters are formed, when small cement particles become embedded in the outer shell of other particles, which promotes the outward growth of these particles. As a hydration progresses, the growing particles become more and more connected and the material changes from the state of a suspension to the state of a porous solid.

In the NIST model [7], the cement particles are represented as a collection of elements (pixels). The model operates on three dimensional images of multi-phase cement particles generated to match specific characteristic of two-dimensional SEM images of real cements. Hydration of cement was simulated by applying a cellular-automata algorithm for dissolution, diffusion, and reaction of the four major cement phases, $C_{3} S, C_{2} S, C_{3} A$ and $C_{4} A F$. Evsukoff et al. [8] presented a data mining approach for modeling the adiabatic temperature rise during concrete hydration.

The objective of this study is to check the ability of the artificial neural networks (ANNs) to predict the adiabatic hydration curve of an arbitrary concrete mixture depending on some parameters, which 
influence the hydration process of cement in concrete. Therefore, the necessary data on the influence of these factors on the adiabatic temperature rise were gathered and analized by our own experiments.

\section{Experimental work}

\subsection{Test equipment and procedure}

To achieve the objective of this study, adiabatic calorimeter of Building Materials Institute IGMAT, which uses air as the coupling media, was used. A ventilator at the top of the chamber guarantees a good circulation of air in the chamber. Adiabatic calorimeter is shown in Fig. 1. The temperature of the concrete in adiabatic calorimeter during the test was measured automatically. Adiabatic calorimeter was connected to the PC and a suitable PC software was prepared for this purpose (see Fig. 1). The temperature was read every 10 minutes, and the duration of one test was about 168 hours (one week). This means that about 1000 data were saved for each concrete mixture.
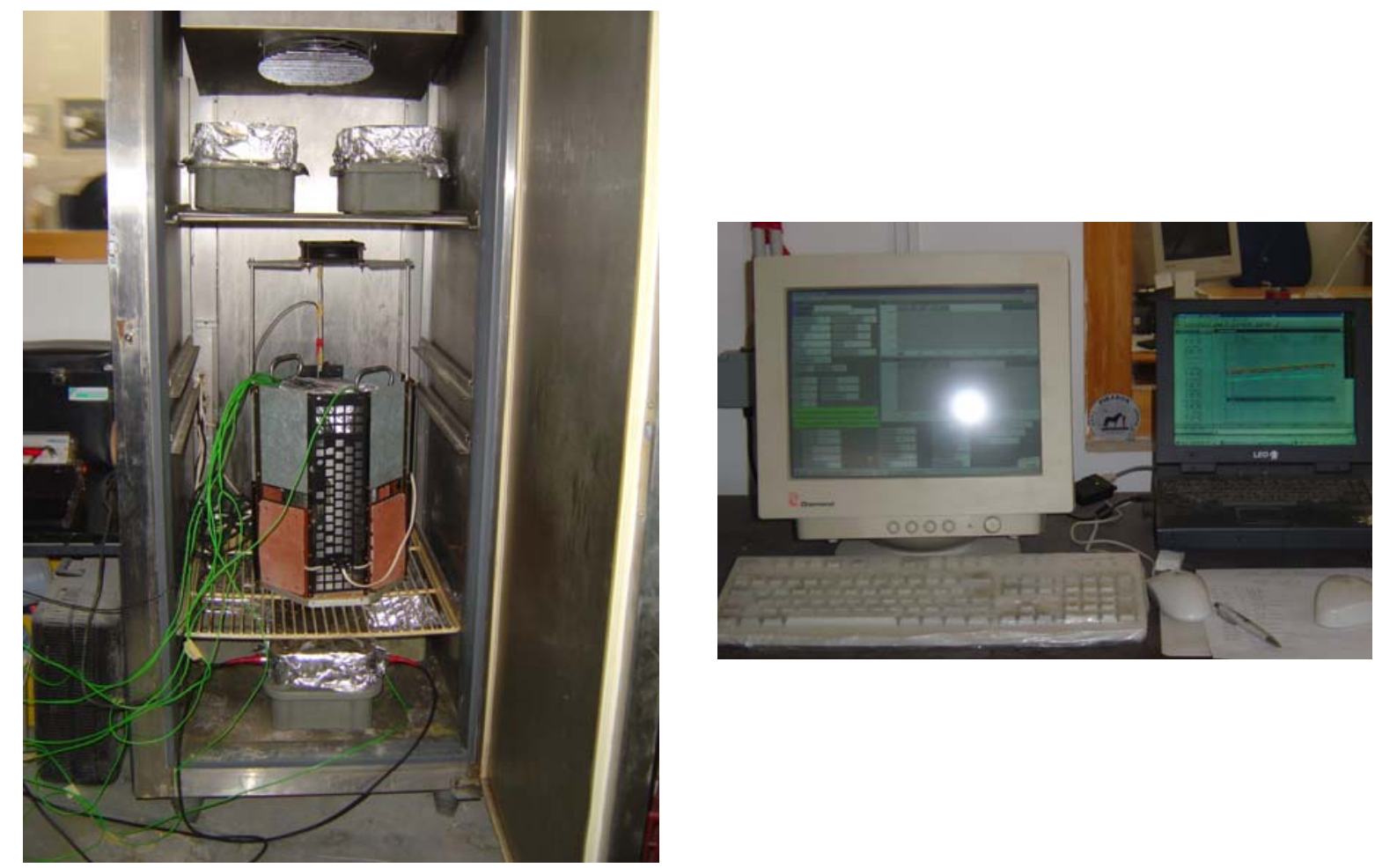

Figure 1: Adiabatic calorimeter of Building Materials Institute IGMAT

Within this study, as many as 22 adiabatic tests were performed. These adiabatic curves are well distributed over the predermined ranges parameter's values. The influence of type of cement, amount of cement, w/c ratio, initial temperature of fresh concrete and the influence of some chemical and 
mineral admixtures on the hydration process of cement in concrete were investigated. Table 1 lists the different parameter values for each mixture.

Table 1: Characteristics of the 22 adiabatic curves.

\begin{tabular}{cccccc}
\hline Label & Initial $T\left[{ }^{\circ} \mathrm{C}\right]$ & Cement type & Am. of cement $\left[\mathrm{kg} / \mathrm{m}^{3}\right]$ & Admixture $[\%]$ & $\mathrm{w} / \mathrm{c}$ \\
\hline A1 & 20 & 1 & 180 & 0 & 0.7 \\
A2 & 25 & 1 & 180 & 0 & 0.7 \\
A4 & 27 & 1 & 180 & 0 & 0.7 \\
SA 30 & 22.9 & 1 & 380 & 0 & 0.42 \\
C1B2 30 & 25.3 & 2 & 350 & 0 & 0.43 \\
PCS 30 & 19.9 & 3 & 350 & 0 & 0.45 \\
PC 30 & 26.5 & 4 & 350 & 0 & 0.45 \\
SA 20 & 23 & 1 & 280 & 0 & 0.65 \\
2082 & 18.7 & 3 & 360 & 0 & 0.5 \\
2083 & 21.3 & 3 & 360 & 0 & 0.5 \\
2084 & 20.7 & 3 & 360 & 2 & 0.47 \\
2085 & 12.6 & 3 & 330 & 2 & 0.45 \\
2086 & 7.2 & 3 & 360 & 0 & 0.47 \\
2087 & 23.8 & 3 & 360 & 0 & 0.5 \\
2088 & 24.9 & 3 & 360 & 0 & 0.5 \\
2089 & 26.2 & 3 & 360 & 0 & 0.5 \\
ZB 002 & 17.37 & 3 & 370 & 0 & 0.54 \\
ZB 004 & 13.08 & 3 & 370 & 0 & 0.54 \\
ZB 005 & 7.89 & 3 & 370 & 3 & 0.5 \\
ZB 103 & 18.49 & 3 & 370 & 3 & 0.5 \\
ZB 105 & 12.85 & 3 & 370 & 3 & 0.5 \\
ZB 107 & 7.94 & 3 & 370 & & 2 \\
\hline
\end{tabular}

\subsection{Experimental results}

Fig. 2a shows all 22 adiabatic hydration curves, which were used in this study. The influence of initial concrete temperature, type of cement, and amount of cement on the hydration process can be seen from Fig 2b, 2c, and 2d, respectively.

It can be seen from Fig. $2 \mathrm{~b}$ that the higher initial temperature of the fresh concrete results in a more rapid hydration process at the very beginning. Interestingly, it finally results in a lower temperature increase at the end of the test. This is a well known phenomenon, which was also observed by some other researchers, for example $[2,4]$. Fig. 2c presents the influence of the type of cement on the hydration process. Four types of cements, used in Slovenia, were used for this purpose. The most intensive hydration process was observed, when cement type CEM II/A-S, 42.5 R (PCS 30) was 
a) All Adiabatic curves, used in this study.

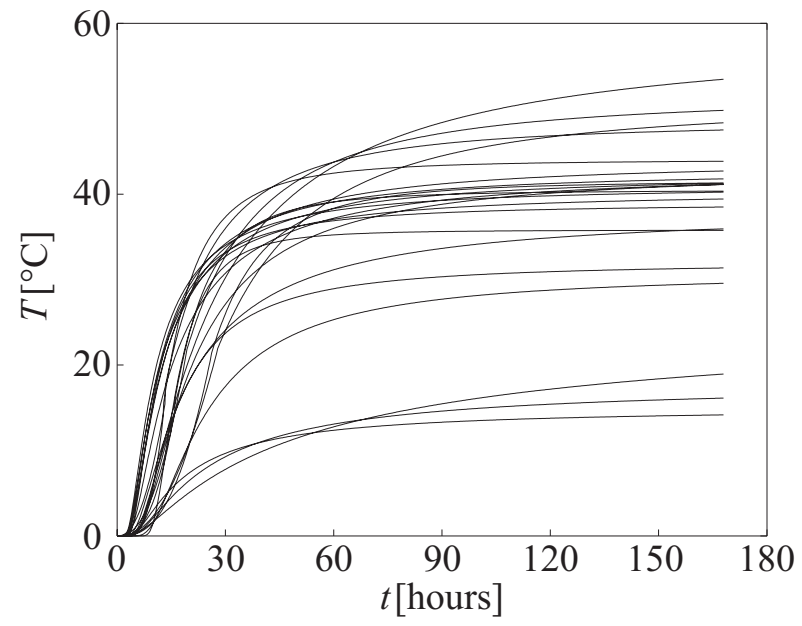

c) Influence of cement type.

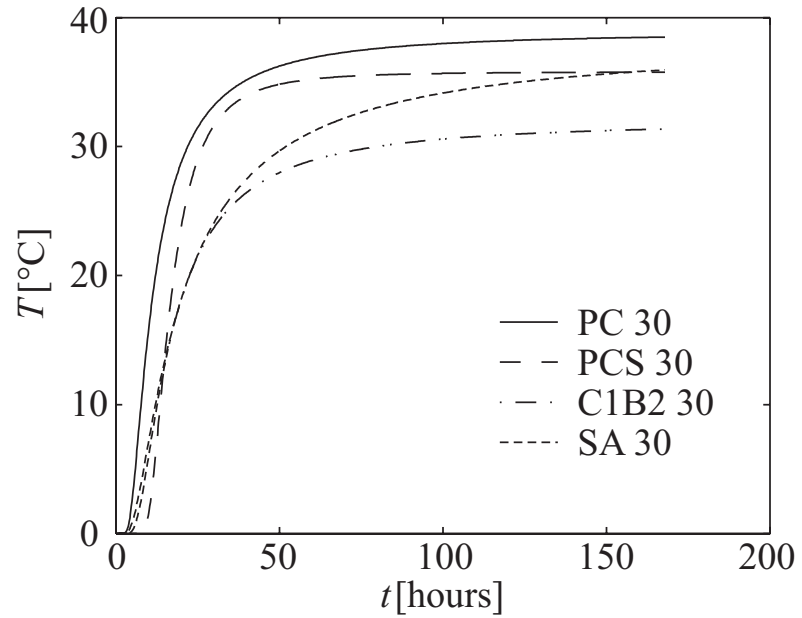

b) Influence of initial concrete temperature.

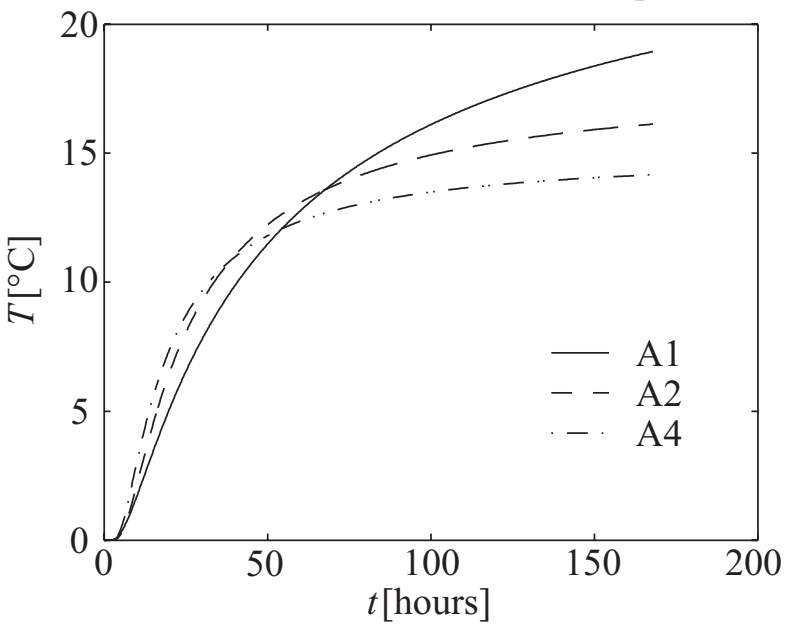

d) Influence of amount of cement.

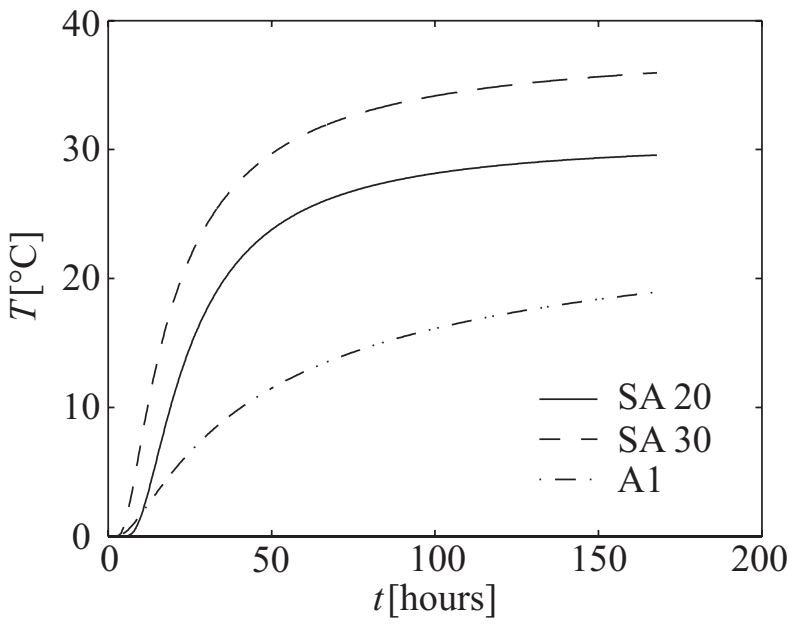

Figure 2: Influence of the parameters on the adiabatic temperature rise.

used. Fig. 2d shows the influence of the amount of cement on the hydration process. It is clear that the higher cement content leads to more rapid hydration process. For a detailed description of these phenomenons reference is made to the literature $[3,4]$.

\section{Artificial neural networks (ANN)}

ANNs are networks consisting of an arbitrary number of very simple elements called neurons. Neurons in ANNs are, similarly to the neurons in human brains, interconnected. The connections are defined by weights. Through connections a neuron receives signal from other neurons. The activation function intensifies or weakens the signal which is transmitted to other neurons.

There are many applications of ANN in structural engineering. Recently, there have been reports on the use of ANN in the modelling the concrete strength, for example $[9,10,11]$, but lately neural 
networks have also been efficiently used for the prediction of concrete compressive strength based on various non-destructive tests $[12,13,14]$. Graham et al. presented a neural network approach for modeling the ready mix concrete delivery system [15].

The multy-layer feed-forward neural networks are usually employed as the approximators of an unknown functional relation [16]. The geometry of a multy-layer feed-forward neural network is shown in Fig. 3. The input units, which represent the input data, are connected to the first layer of hidden units, which are further connected to the units of the next hidden layer. The units of the last hidden layer are connected to the output units, which represent the output data.

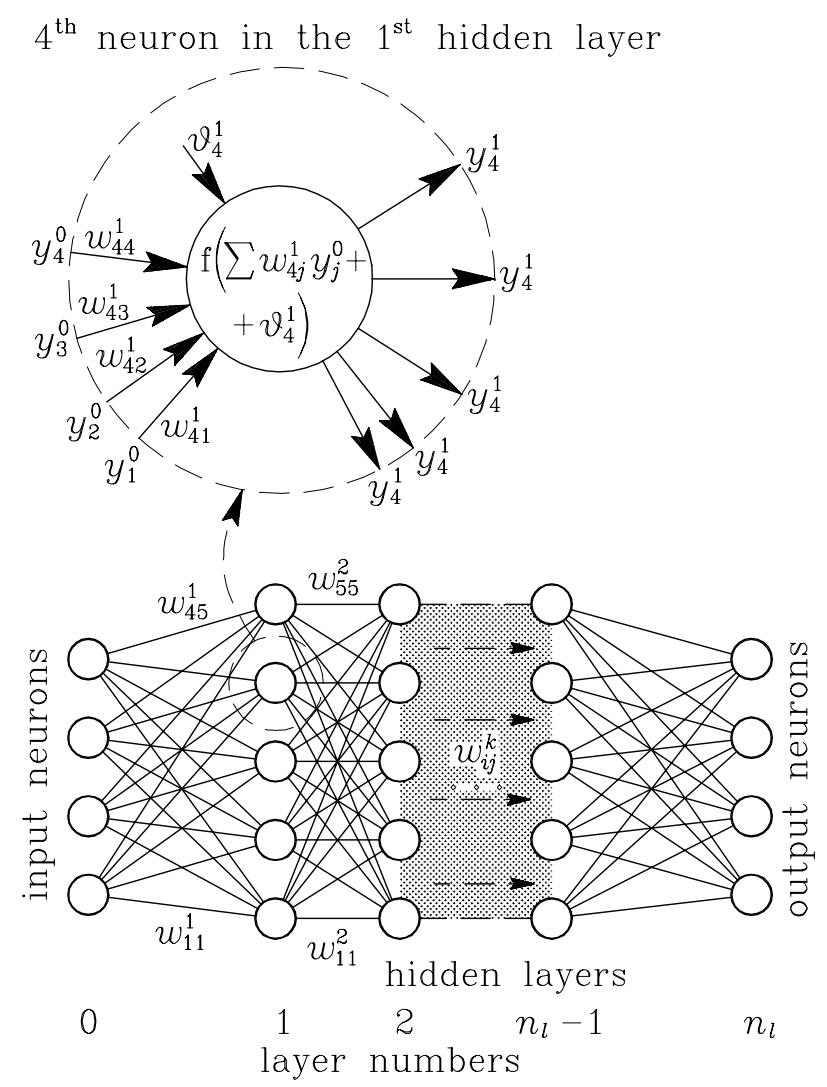

Figure 3: Multi-layer feed-forward artificial neural network.

Each unit is represented by its value $y_{i}^{k}$. Each connection between the units is characterized by its weight $w_{i j}^{k}$. The index $i$ corresponds to the unit number of $k^{\text {th }}$ layer, while index $j$ corresponds to the unit number of the $(k-1)^{\text {th }}$ layer. The value of a unit is multiplied by the corresponding weight and added to the value of the signal in the unit of the next layer. In addition, the value of bias neuron or 
threshold $\vartheta_{i}^{k}$ is added to the equation

$$
y_{i}^{k}=f\left(\sum_{j=1}^{n_{k-1}} w_{i j}^{k} y_{j}^{k-1}+\vartheta_{i}^{k}\right),
$$

which is illustrated in Fig. 3. Activation function $f($.$) , which is usually the sigmoid function$

$$
f(y)=\frac{1}{1+\exp (-y)}
$$

enables the modelling of an arbitrary continuous nonlinear relation between input and output variables.

The set of known input and output values is termed an input-output pair. All pairs are divided into two sets. The first one is termed as the learning or training set (about $75 \%$ of all data), which is

used to determine the connection weights $w_{i j}^{k}$ and thresholds $\vartheta_{i}^{k}$. When the learning procedure ends, meaning that the neural network performs adequately for all input-output pairs in the learning set, the performance of the neural network is assessed on the testing data.

In some cases the training procedure becomes ill-conditioned if the input and/or output data are not normalized (see e.g. [17]). Therefore, for numerical reasons, the values of the input and output data have to be normalized. The normalization of the values of output units depends on the range of the activation function $f$.

The training procedure is in fact a general optimization problem in which the minimum of error $E_{p}$ is sought

$$
E_{p}=\frac{1}{2} \sum_{i=1}^{n_{0}}\left(T_{p i}-y_{p i}^{n_{l}}\right)^{2},
$$

where $t_{p i}$ are the target output values, $y_{p i}^{n_{l}}$ are the values of neurons in the output layer $n_{l}$, i.e. the output values evaluated by $\mathrm{ANN}, n_{0}$ is the number of neurons in the output layer, i.e. the number of output variables. This problem is numerically very demanding since a large number of local minima usually exist. There are two essentially different approaches: error back-propagation (BP) algorithms (which are basically a gradient method) and genetic algorithms (which are in fact a stohastic search).

\section{Construction of ANN model}

A typical MFNN has three or more layers: the input layer, one or more hidden layers and the output layer. While learning, the neural network store the non-linear information between the influencing factors and the adiabatic temperature rise $T$ in the weight matrix in a dynamic and parallel way, and 
the network can give the corresponding output upon the input factors while recalling. As the problem was defined as a nonlinear input-output relation between the influencing factors and the adiabatic temperature rise $T$, this led us to choose, for our ANN, the 6-30-30-30-1 architecture. Therefore, there are six neurons in the input layer, corresponding to the five influencing factors (see Table 1) and the time $t$, thirty in each hidden layer and one in the output layer corresponding to the adiabatic temperature rise $T$. The neurons of successive layers are fully connected.

The batch of data has been divided into two sets, one for the ANN learning called a learning set and the other for testing the ANN called a testing set.

Two studies were done in order to establish the ability of ANN to predict adiabatic hydration curves of arbitrary concrete. Within the first study, concrete mixtures with the same cement type were taken into account, while within the second study, all data were used (see the following sections).

\section{Teaching and testing the network}

\subsection{Study 1: Data for cement type 3}

Most of the concrete mixtures were prepared with cement type 3 , which is one of the most frequently used type of cements in Slovenia. Therefore, in this study twelve curves, labeled PCS 30, 208 2, 208 3, 208 4, 208 8, 208 9, ZB 002, ZB 004, ZB 005, ZB 103, ZB 105 and ZB 107 (see Table 1) were used for teaching the ANN and curve 2087 was used for testing. Within this study, the cement type was the same for all concrete mixtures, so the number of input neurons was reduced to five. In this case, none of the input parameters of curve 2087 had extreme value with respect to parameter values of all other curves analyzed here. We stopped the learning process when the iterations reached 1000, and the grand total learning error (see Eq. 6) was 0.025. Fig. 4a is an expression of the learning results, each point standing for a learning vector. The nearer the points gather around the diagonal, the better are the learning results. Thus, the learning errors of the points on the diagonal are zero. It can be seen from this Fig., that the 5-30-30-30-1 ANN predicted the testing values with a high accuracy.

The coefficient of correlation was $R^{2}=0.9995$ in this case, while the root mean square error (RMSE), defined by

$$
R M S E=\sqrt{\frac{1}{N} \sum_{e=1}^{N}\left(T_{e, A N N}-T_{e, \exp }\right)^{2}}
$$


a)

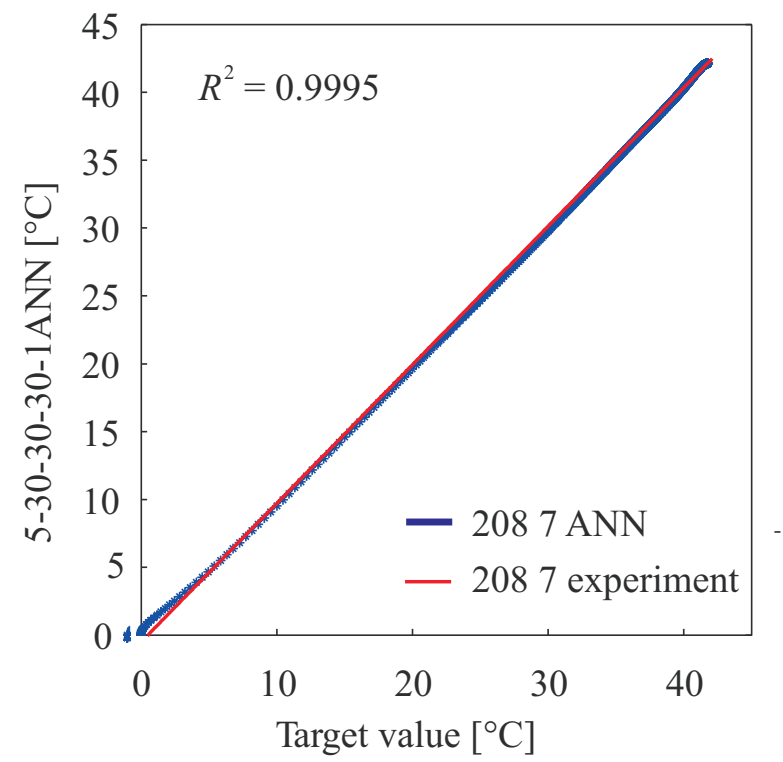

b)

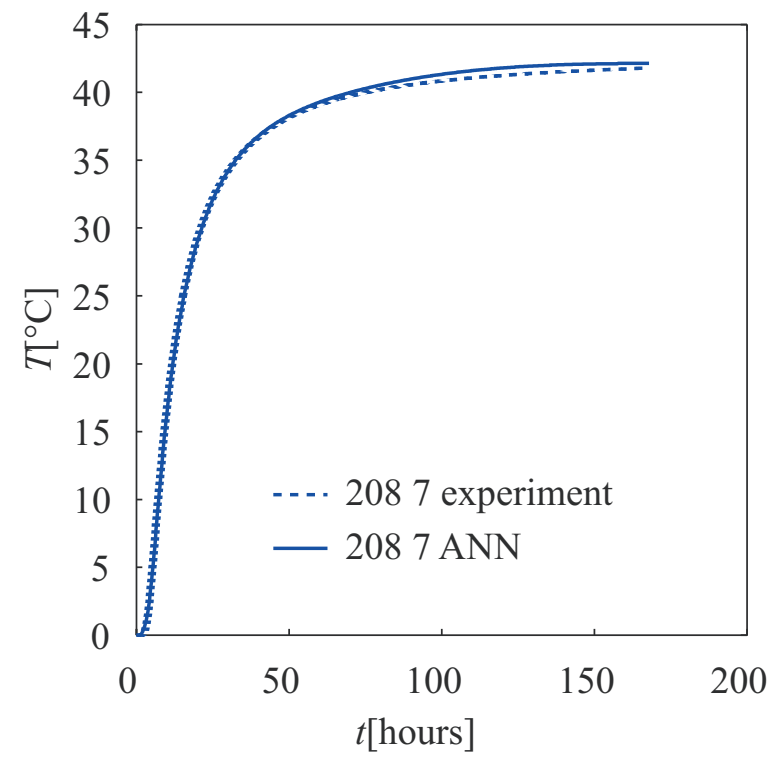

Figure 4: Comparison between actual and calculated values of relative temperature.

was 0.2006 . In Eq. $7 N$ is a number of all testing data, $T_{e, A N N}$ is the value of temperature rise at time $t_{e}$, evaluated by the ANN model and $T_{e, \exp }$ is the the value of temperature rise at time $t_{e}$, determined by experiment.

Fig. 4b presents the testing adiabatic curve 2087 , which was obtained by experiments (dashed line) and the same curve, obtained by ANN (solid curve). In this case ANN model attain very good prediction accuracy.

\subsection{Study 2: All data}

In this study all data were used for teaching the ANN, except curve 2083 which was used for testing. At first, the curve 2082 was eliminated from the learning set, so the initial temperature $T_{\text {init }}$ of concrete 2083 was the lowest among all other initial temperatures of the concretes with the same remaining four input parameters $(208$ 7, 208 8, 208 9) as in the case of concrete 2083 (see Table 1). The coefficient of correlation between actual and calculated values was $R^{2}=0.9969$ and the $R M S E$ was 0.5115 . Fig. 5a shows the correlation between actual and calculated values in this case.

Next, the curve 2082 was included in the learning set, so the initial temperature $T_{\text {init }}$ was not the lowest any more. The coefficient of correlation between actual and calculated values was $R^{2}=0.9989$ in this case and the RMSE value was 0.3358. Fig. 5b shows the correlation between actual and calculated values in this case. Therefore the accuracy of prediction was better than in the case when 
a)

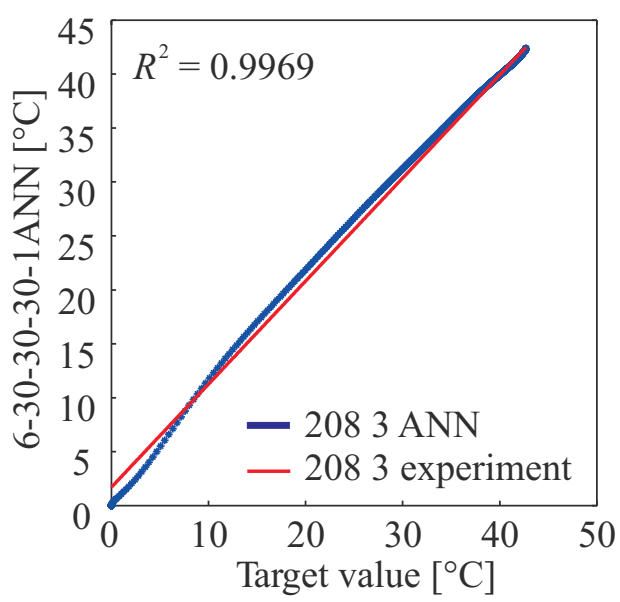

b)

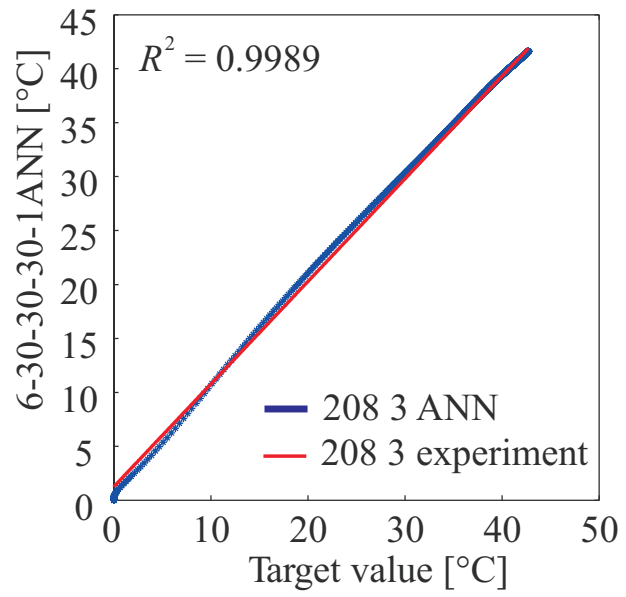

Figure 5: Comparison between actual and calculated values of relative temperature. a) without 2082 , b) with 2082.

the curve 2082 was not included in the learning set. This indicates that ANN has good capability of interpolation but is not as efficient in the case of extrapolation.

\subsection{Use of the ANN model - example}

When the learning and testing procedure were finished and all the weights $w_{i j}^{k}$ were established, the programme was installed within Matlab programming environment. The weights from the $2^{\text {nd }}$ study were used for this purpose. The adequateness of the proposed model can be observed from Fig. 6, where the influence of the initial temperature of fresh concrete mixture is shown. The well known phenomenon, which was explained in section 2 , is observed again. The higher initial temperature leads to the more rapid hydration process at the very beginning and finally results to the lower temperature increase at the end of the test. It can also be seen from Fig. 6, that a small deviation in the initial temperature $T_{\text {init }}$ leads to an important and well observed change in the adiabatic hydration curves. Therefore, we conclude the proposed ANN model was quite sensitive.

The initial temperatures of the dashed, dotted and solid curves were $22^{\circ} \mathrm{C}, 22.5^{\circ} \mathrm{C}$ and $23^{\circ} \mathrm{C}$, respectively and the other initial parameters were as follows: cement type 3, amount of cement 350 $\mathrm{kg} / \mathrm{m}^{3}, \mathrm{w} / \mathrm{c}$ ratio 0.47 and amount of admixtures 0 .

The computer programs, which are used for prediction of the thermal fields and thermal cracking in young concrete are usually implemented in the finite element or finite difference codes. One of the main inputs in such analysis is the adiabatic temperature rise curve. Unfortunately, it is often 


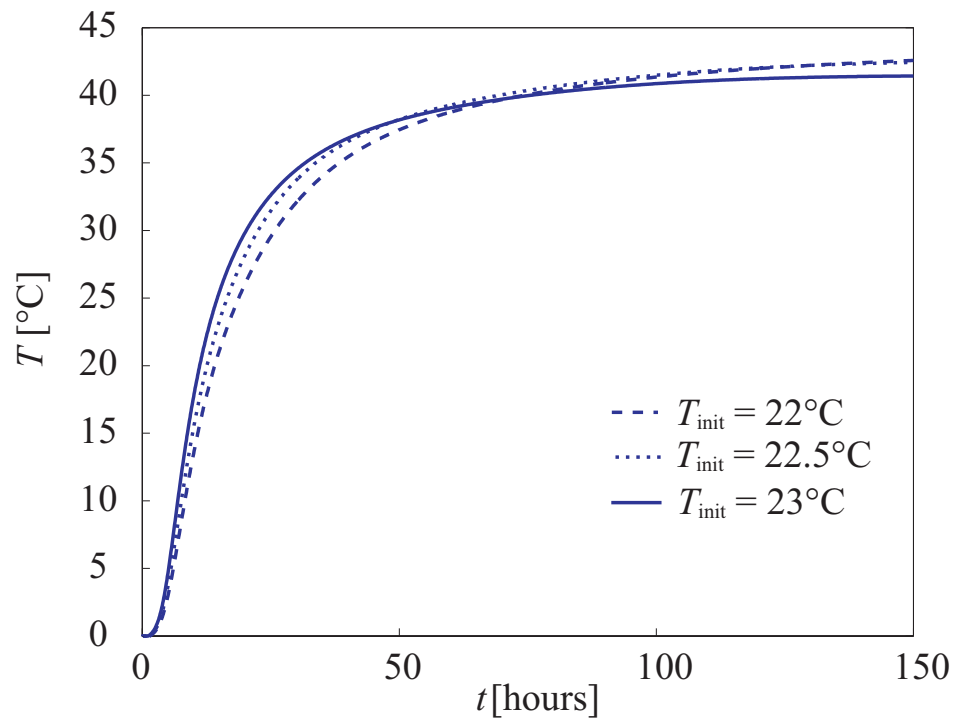

Figure 6: Influence of the initial temperature on the adiabatic temperature rise with ANN model.

time-consuming and difficult to determine the corresponding adiabatic hydration curve. The presented numerical model can be easily incorporated in such computer program and the adiabatic hydration curve can be determined only by entering a variable data set corresponding to the binder physical and chemical properties and concrete mixture proportions.

\section{Conclusions}

The ANN-based model was developed for predicting the adiabatic temperature rise curve of different concrete mixtures. This way, a very good agreement of calculated adiabatic hydration curves and adiabatic hydration curves, obtained by our experiments in suitable adiabatic calorimeter was achieved. It was shown that the learning data are very important and meaningful for the accurate prediction of adiabatic hydration curves. These data have to be selected properly and have to be well distributed over the predetermined ranges of variability. New adiabatic hydration curves with some other initial parameters of the concrete mixture can be easily included in the learning set in order to expand the range of suitability of ANN to predict the adiabatic hydration curves.

The presented ANN model of adiabatic curves can be easily incorporated in computer programs, based on finite element or finite difference method, which are used for prediction of thermal fields and thermal cracking in young concrete.

Proposed model attains a good prediction accuracy. Some effects of concrete initial parameters 
(for example the initial temperature of fresh concrete) on adiabatic temperature rise are in good accordance with the well known rules of mix proportioning and other initial characteristics of fresh concrete mixture. Consequently, the application of ANN models to predict the adiabatic hydration curves of concrete is practical and has a prospect of application in construction practice.

\section{Notations}

The following notations are used in the paper:

ANN artificial neural network

T adiabatic temperature rise $\left[{ }^{\circ} \mathrm{C}\right]$

$t \quad$ time

$a, b, c, d, m, n \quad$ empirical constants

$T_{\infty} \quad$ temperature at the end of the hydration process

$y_{i}^{k} \quad$ output of neuron $i$ in layer $k$

$y_{j}^{k-1} \quad$ output of neuron $j$ in layer $k-1$

$w_{i j}^{k} \quad$ connection between neuron $i$ in layer $k$ and neuron $j$ in previous layer

$\vartheta_{i}^{k} \quad$ threshold value

$n^{k} \quad$ number of layers

$f(\cdot) \quad$ activation function

$E_{p} \quad$ error between target temperature value $T_{p i}$ and predicted temperature value $y_{p i}^{n_{l}}$

$n_{0} \quad$ number of all neurons in output layer

$n_{l} \quad l^{\text {th }}$ output layer

$T_{\text {init }} \quad$ initial temperature of concrete

$R M S E$ root mean square error

$N \quad$ number of all testing data

$T_{e, A N N}$ value of temperature rise at time $t_{e}$, evaluated by the ANN model

$T_{e, \exp } \quad$ value of temperature rise at time $t_{e}$, determined by experiment 


\section{References}

[1] J. Zach, H. Kminova, O. Horky, J. Brozovsky, Determination of intensity of hydration heat development of silicate binders, in Proc. The 8th International Conference of the Slovenian Society for Non-Destructive Testing, Application of Contemporary Non-Destructive Testing in Engineering, Portorož, Slovenia, 2005, 375-382.

[2] K. van Breugel, Simulation of Hydration and Formation of Structure in Hardening Cement-Based Materials - HYMOSTRUC, Ph.D. Thesis, Second Edition, Delft University of Technology, 1997.

[3] G. Trtnik, The Influence of Chemical Admixtures on Cold Weather Concreting (in Slovenian), B.Sc. Thesis, University of Ljubljana, 2004.

[4] F. Kavčič, Hydration process of cement in concrete at the adiabatic conditions (in Slovenian), M.Sc. Thesis, University of Ljubljana, 2000.

[5] P. Morabito, Apparent Activation Energy, An example of determination from adiabatic hydration tests, IPACS Report BE96-3843/2001:19-2, Lulea, Sweden, 2001.

[6] C. Ammar, P. Dutron, H. Motteu, J. Dubois, La progression des betons et des mortiers par basses temperatures, C.S.T.C.-C.R.I.C.-SECO, Bruxelles, 1973.

[7] D.P. Bentz, CEMHYD3D: a three-dimensional cement hydration and microstructure development modelling package. Version 3.0, NISRTIR 7232, U.S. Department of Commerce Technology Administration, Gaithersburg, Maryland, 2005.

[8] A.G. Evsukoff, E.M.R. Fairbairn, E.F. Faria, M.M. Silvoso, R.D.T. Filho, Modeling adiabatic temperature rise during concrete hydration: A data mining approach, Computers and Structures $84(31-32)$ (2006) 2351-2362.

[9] S.C. Lee, Prediction of concrete strength using artificial neural networks, Engineering Structures 25 (7) (2003) 849-857.

[10] H.G. Ni, J.Z. Wang, Prediction of compressive strength of concrete by neural networks, Cement and Concrete Research 30 (8) (2000) 1245-1250. 
[11] S. Lai, M. Serra, Concrete strength prediction by means of neural network, Construction and Building Materials 11 (2) (1997) 93-98.

[12] J. Hola, K. Schabowicz, Application of artificial neural networks to determine concrete compressive strength based on non-destructive tests, Journal of Civil Engineering and Management, 11 (1) (2005) 23-32.

[13] M.A. Kewalramani, R. Gupta, Concrete compressive strength prediction using ultrasonic pulse velocity through artificial neural networks, Automation in Construction 15 (3) (2006) 374-379.

[14] J. Hola, K. Schabowicz, New technique of nondestructive assessment of concrete strength using artificial intelligence, NDT\&E International 38 (4) (2005) 251-259.

[15] L.D. Graham, D.R. Forbes, S.D. Smith, Modeling the ready mix concrete delivery system with neural networks, Automation in Construction 15 (5) (2006) 656-663.

[16] T. Ambrožič, G. Turk, Prediction of subsidence due to underground mining by artificial neural networks, Computers and Geosciences 29 (5) (2003) 627-637.

[17] W.S. Sarle, Neural network FAQ. Periodic posting to the Usenet newsgroup comp-ai.neuralnets. URL: ftp://ftp.sas.com/pub/neural/FAQ.html; 10.07.2007. 